\title{
Anti-Immigration Backlashes as Constraints
}

\section{Lorenzo Del Savio ${ }^{1}$}

Accepted: 23 December 2019 / Published online: 10 January 2020

(C) The Author(s) 2020

\begin{abstract}
Migration often causes what I refer to in this paper as 'anti-immigration backlashes' in receiving countries. Such reactions have substantial costs in terms of the undermining of national solidarity and the diffusion of political distrust. In short, anti-immigration backlashes can threaten the social and political stability of receiving countries. Do such risks constitute a reason against permissive immigration policies which are otherwise desirable? I argue that a positive answer may depend on a skeptical view based on the alleged constraints that certain political facts - especially facts about human nature - pose on political intervention. This view does not stand conceptual and empirical scrutiny in the case of anti-immigration backlashes, where feasibility comes in degree. Yet focusing on the recalcitrance to change of these facts is practically important when devising action plans. This pragmatic core of the skeptical view yields a gradualist and naturalistic way of thinking about constraints in political theorising about migration, and elsewhere.
\end{abstract}

Keywords Migration $\cdot$ Feasibility $\cdot$ Exclusivism $\cdot$ Populism

\section{Introduction}

Our best economic and political theories recommend less restrictive immigration policy than those that are the norm in rich countries (or so I will argue in section 3). As a consequence of extant restrictions, illegal access and employment in the informal sectors of the economy are the only options for many immigrants. Labour abuses and avoidable deaths ensue. These consequences, and the vast harmful consequences of border enforcement, strenghten the case for less restrictive immigration policy. And yet, despite such restrictions, there have been antiimmigration backlashes in several wealthy countries in recent years.

Xenophobic, anti-immigration parties have been on the increase. Their leaders have been appointed to key governmental positions. Such parties have enacted more restrictive

Lorenzo Del Savio

lorenzo.delsavio@1mu.de

1 Ludwig-Maximilians-Universität München, Geschwister-Scholl-Platz 1, 80539 Munich, Germany 
immigration policy once in power. They have also steered other more mainstream political parties to take on restrictive stances. Citizens' attitudes and beliefs in receiving countries additionally attest to such backlashes. The number of migrants is consistently overestimated. Cultural concerns for immigration are widespread and, in a few cases, majoritarian (Pew research center 2018). In a number of countries, there have been public demonstrations against the relaxation of restrictive migration policy. Outright xenophobic violence is not uncommon.

Non-restrictive migration policy may be rejected by the populace or a part of it even if established through a political process whose output is generally accepted. Such rejection may also spill over. It may disseminate distrust towards the political system as a whole and lead to a generalised repudiation of policy outputs which have in principle nothing to do with immigration. If citizens do not share fundamental beliefs and values with the bodies that enact policy, they might stop complying with its decisions. Migration policy apparently involves such fundamental beliefs and values. Such a spillover is arguably what we are witnessing with the rise of anti-immigration parties in wealthy countries: the political agendas of these parties differ, but they share a broadly anti-elitist agenda that targets the political system in its entirety. Anti-immigration backlashes have therefore substantial costs in terms of political stability.

This article addresses the question: what shall we do with the costs of anti-immigration backlashes when reasoning about what migration policy is best? In the next sections I will argue, in this order: that the costs of anti-immigration backlashes are vast and potentially underestimated (section 2); that we have powerful reasons to adopt less restrictive immigration policy, independently from these costs (section 3); that the costs of anti-immigration backlashes cannot count against the latter reasons because they are themselves under moral scrutiny and because the opposite view is based on an untenable view of how such political constraints function (section 4); that anti-restrictionist theorists of immigration should nonetheless engage with anti-immigration backlashes and, more generally, issues of feasibility by employing whatever tools empirical research on anti-immigration backlashes and human beahvior more generally supplies (section 5). The aim of this article is to combine the reformist spirit that animates anti-restrictionist theorists (and activists) of immigration with what can be rescued of the skeptical gaze of a conservative worldview, which fears the real-world consequences of our best hopes for change, thereby questioning their feasibility. The novel contributions of this article are: a discussion of the causes and consequences of anti-immigration backlashes that compares the latter to the alleged costs of immigration itself; and the claim that oftentimes even though not always — debates regarding the normative relevance of feasibility are motivated by two different general views on political matters, a reformist and a conservative one, which can however be usefully combined.

\section{The Social and Political Costs of Anti-Immigration Backlashes}

Among those who argue that migration should be restricted, it is common to highlight the threats which immigrants pose for the political and economic system of receiving countries. Migrants may bring with them habits and attitudes which are at odds with local culture. Specifically, migrants may allegedly erode those aspects of the local culture which are not only arbitrarily valued by residents as a matter of mere taste but even those societal features which are foundations of the political and economic success of their country. Trust in others and in the state organs, attitudes towards the participation of women in the labour market, propensity to spend and save: these and others are all traits that are heterogeneously distributed in the 
populations of different countries. Such distributions can be hence transformed by international mobility, at least if and to the extent that such traits move along with people. Nations indeed differ in terms of economic success and political stability, and some determinants of such success may, as it were, stick to migrating people through a variety of mechanisms, intragenerationally as well as intergenerationally. ${ }^{1}$ On this basis, even a distinct thread of pro-market arguments against specific types of migration has emerged, despite the general sympathy for open borders of economic liberals (Slobodian 2018). The argument is that economic migration can be self-defeating. It is self-defeating if it undermines the foundations of that prosperity that attracts immigrants in the first place. $^{2}$

Seldom discussed in this context is, however, the threat that anti-immigration backlashes themselves pose for these same social and political foundations. This is perhaps not surprising when arguments in favour of restriction come from avowedly anti-immigration groups, as antiimmigration residents rather than migrants are in this case the main culprits. If we, however, set aside issues of responsibility which are of little relevance for these types of cost-benefit analyses we notice that there are important similarities between the two phenomena. To be sure, the mechanism does differ in the two cases. In one case, migrants bring new sets of attitudes and behaviours. In the other case, residents change their attitudes and behaviours as a result of migration. The outcomes would be, however, structurally similar if both of these mechanisms were instantiated in a country. In both cases the composition of the resident population and their beliefs, attitudes and behaviours would shift. In fact the very same traits might shift as a result of the two mechanisms, including traits which are singled-out as determinants of prosperity in pro-market anti-immigration arguments, such as for instance trust in others.

There are reasons to believe that anti-immigration backlashes do generate such harmful shifts in attitudes and behaviours. These reasons are at least as good as the analogous evidence for the mechanism feared by anti-immigration economic liberals. In what follows, the focus will be on two kinds of harmful consequences which may occur as a result of anti-immigration backlashes: social and political. This is not exhaustive. The sole aim of this section is to provide evidence that such damages cannot be overlooked in normative discussions of migration policy: the next sections will be dedicated to how, exactly, these costs should be taken into account.

\subsection{The Undermining of Social Solidarity}

It has been argued that one reason Nordic countries have comparatively larger welfare states than other affluent countries is because they have had historicall, more homogeneous populations (e.g. Alesina et al. 2001; Alesina and Glaeser 2004). A generous welfare state is due, according to these theories, not so much or not only to a history of conflictual bargaining between capital and labour but to widespread social solidarity (Kymlicka 2015). Social solidarity depends in turn on prosocial feelings, attitudes and behaviours which are facilitated by cultural, linguistic and religious homogeneity. Moreover, a sense of nationhood that transcends class divisions is itself predicated on such homogeneity. Ever since the formulation

\footnotetext{
${ }^{1}$ For instance: Rice and Feldman (1997) describe the intergenerational persistence of civic virtues by following the European heritage of US citizens. Current levels of civic virtues in the US map with current levels of civic virtues in countries of origin, even if three generations have in some cases passed. The inheritance mechanism is most likely to be cultural in this case. Other inheritance mechanisms are, however, also conceivable.

${ }^{2}$ Del Savio et al. (2019) discuss these issues more in depth.
} 
of such theories, a vast body of evidence on population diversity and social solidarity has been collected with few consensual conclusions: the effects seem to be geographically limited and somehow more robust in the US (Schaeffer 2013; Van der Meer and Tolsma 2014). Yet the mechanisms which are hypothesised in such theories deserve attention in this discussion.

The key point is that the determinants of social solidarity, namely prosocial feelings, are supportive not only of generous welfare states — if indeed they are — but also of a wide set of institutions which underlie political and economic success, including for instance functioning markets. A sense of belonging and trust in others promotes an 'everyday sociality' (Bowles and Gintis 2011) that makes any form of social cooperation viable, including the contractual arrangements validating commercial transactions. ${ }^{3}$ Such general-purpose everyday sociality is important whatever one thinks of robust welfare states. It would be important even if the nexus between population homogeneity and size of welfare provision were disproven. Increased diversity in terms of habits, norms and beliefs may make social coordination more complicated; ensuing misunderstandings may in turn reduce the payoffs of everyday sociality and increase the chances of interpersonal conflict. By increasing diversity, migration could trigger this: thereby endangering social solidarity.

A potential reply to this concept is that immigration is just one source of social diversity. In many nations, religion is a divisive factor irrespective of recent migratory influxes. Singling out immigration as a specific threat for social homogeneity seems, therefore, to be purely arbitrary or tinged by methodological nationalism and xenophobia. There are, after all, several ways to parse social diversity. Why focus on the types of diversity created by immigration? Of course, a focus on migration is sometimes motivated by the nationalism and xenophobia of the theorist. A focus on migration can be arbitrary and malicious. Nationalism and xenophobia may, however, be sufficiently widespread to generate an independent mechanism by which increased migration-related diversity undermines social solidarity.

It is conceivable that several processes could establish an association between increased population diversity and decreased social solidarity. The hypothesis here is that xenophobia is a necessary component of one such process. That is, a lack of coordination and the increased costs of cooperative interactions may be caused, or anyway heightened, by the presence of xenophobic and nationalist attitudes in the population of receiving countries. Some failures to cooperate would then be a consequence of hatred of strangers. How much such a mechanism is important in comparison to other channels (if indeed there are any) is an empirical question. Yet the very presence of xenophobic and nationalist attitudes makes such a mechanism plausible and entails, moreover, that the study of this mechanism is not a form of methodological nationalism. This is one central tenet of this article: whatever we think normatively of xenophobic or nationalist attitudes, when reasoning about the effects of migration they are also important data.

The hypothesis that anti-immigration attitudes as such undermine social solidarity is important here because the latter is thought to be a major determinant of prosperity. It has been claimed that social trust, in particular, plays such a role (e.g. Fukuyama 1996). Social trust is indeed associated with the wealth and population health of nations. In addition, social trust might itself be valuable — being part of prosperity, as it were — as it is also associated

\footnotetext{
3 "By cooperation we mean engaging with others in a mutually beneficial activity. Examples include the joint pursuit of political and military objectives as well as the more prosaic foundations of everyday life: collaboration among employees in a firm, exchanges between buyers and sellers, and the maintenance of local amenities among neighbors" (Bowles and Gintis 2011, pg.3).
} 
with reported well-being independent of other factors known to contribute to happiness (Hamilton et al. 2017). The spread of xenophobic attitudes may weaken social trust. If it does, the effects could be more severe in the presence of consistent immigration as a larger part of the population is perceived to be composed of strangers. Xenophobia is, etymologically speaking, the fear of strangers or guests. Reciprocal fear and suspicion are nothing less than classical symptoms of a decaying social order. As such harmful consequences pertain to citizens' interpersonal relationships, they may be defined as 'the social costs' of antiimmigration backlashes.

\subsection{Populism}

Anti-immigration backlashes might generate a specifically political form of distrust, which relates to the relationship between citizens and the state. Governments and other state organs which enact non-restrictive migration policy may be depicted as agents of foreign individuals, such as the migrants themselves but also powerful international elites. They may also be depicted as failing their purported democratic mandate of being the agent of the people, conceived as the unitary whole of the residents of a country or a homogeneous subset thereof. These are central features of populist politics. Populism has been defined as a "moralised form of anti-pluralism" that speaks "in the name of the people as a whole" (Müller 2017, p. 20). 'Usversus-them' political rhetoric magnifies this central feature of populist politics. Populism is hence facilitated by migratory influxes, exacerbating an ethno-linguistic notion of a unitary 'us'. Granted, in the absence of immigration, a populist rhetoric will target other minorities. Yet, although anti-immigration backlashes are not a necessary factor for the emergence of populist forces, migration is a fertile soil for the growth of such forces. Forms of moralised anti-pluralism and the anti-elitist conceptions of the people are easily grafted onto ethnoxenophobic or nationalist rhetoric.

In addition to the opposition between the people and the elite, populists claim to defend national popular sovereignty (Mudde and Kaltwasser 2013) and may spread anti-expertise attitudes in the population alongside their anti-elitist rhetoric. These are self-reinforcing features of the populist complex, a tightly connected cluster rather than a loose set of properties. The importance of national popular sovereignty is the evaluative foundation of the claim that foreign elites have defrauded the people of democratic control. Expertise is contested as an ideology that supports the extant status quo and the power of alien elites. These features of the populist complex can in turn be integrated with anti-immigration rhetoric. For the populist, migration contributes to the dissolution of national sovereignty of which borders are a key component. These are more than hypothetical discourses, which are conceptually plausible but play no role in actual political behaviour. Anti-immigration attitudes are known to be a central driver of populist politics, at least in wealthy countries (Mudde 2007).

What is the cost of populism? The three central features of populism - moralised antipluralism, an unyielding defence of national sovereignty and anti-elitism - have distinct harmful consequences. Moralised anti-pluralism weakens representative democracy by contesting the mediating role of both public debates and those structures which limit the sovereign, democratic aspects of the political system such as a free press, the parliament and an independent judiciary (Urbinati 2017). Authoritarian leadership also belongs to that part of the populist syndrome that affects political representation as, in a populist moment, immediate identification with a leader replaces trust in mediating procedures. An unyielding defence of national sovereignty, in contrast to pragmatic and flexible approaches, will damage those 
aspects of sovereign devolution to international bodies which promote peace and economic growth. Anti-elitism, and the targeting of experts as such, might lead to the election of incompetent representatives and government officials. Anti-expertise attitudes may spread, thus disrupting the delicate functioning of the cognitive division of labour and power that supports prosperity.

The extent of such damage depends on how well representative democracy, the devolution of national sovereignty and the extant division of epistemic power are performing. Populism, as a political complex, can reinforce the democratic aspects of a political system if detached from its anti-immigrationist, exclusivist components: at least in contexts where democracy has been curbed. Yet in wealthy countries, those where anti-immigration backlashes are more likely, the risk that populism will actually be destructive is high, as the political system usually is, in a prosperous country, functioning and stable. Here, the politically harmful effects of antiimmigration backlashes may be severe quite independently from the harm they engender to immigrants and would-be immigrants.

Social trust and the political support of a functioning representative democracy are thought to be among the central prerequisites of prosperity. Depending on whether the claims regarding the costs of migration due to the attitudes and behaviours of migrants are substantiated, antiimmigration backlashes may eventually turn out to be the most conspicuous cost of migration. This is another way in which migration can be self-defeating, vastly different from the one dreaded - in good or bad faith — in pro-market arguments against open borders. This twist in the debate can and should be used to oppose vicious forms of hateful xenophobic rhetoric. Yet rhetorical countermoves may not, on their own, be sufficient to avert anti-immigration backlashes and their harmful consequences.

\section{Migration and the Lag between Theory and Practice}

In the face of the substantial costs discussed in the previous section, one may think that the best approach would be the adoption of a most cautious approach to immigration policy in countries that may face backlashes. The trouble with this approach, however, is that a number of different arguments for anti-restrictionist immigration policy are, taken together, very powerful. Since extant immigration policy tends to be restrictive, there is a lag between theory and practice in immigration policy, and anti-immigration backlashes seem to be one key cause of such lag.

What are these arguments in favour of non-restrictive immigration policy? Political theorists studying migration often starts from the question, 'Do states and their citizens have the right to exclude would-be immigrants?' This is sometimes taken to be the most important question in the political theory of migration (Blake 2016; Bertram 2018). Both negative and positive answers have been given and defended. ${ }^{4}$ Negative answers relate to the idea that imposing any restriction on immigration would be unjust or, at least, that most extant restrictions are unjust as some of these theories allow for limitations on immigration in special circumstances. Restrictions on migration are the exception rather than the rule for those who

\footnotetext{
${ }^{4}$ Theorists who admit restrictions on migration are, for example: Walzer (1995), Miller (2005), Wellman (2008), Blake (2013). Theories that instead prohibit most restrictions are those defended by Cole (2000), Huemer (2010), Carens (2013), Oberman (2016), Bertram (2018). Different theories admit or prohibit restriction to a greater or lesser degree. Rather than two neatly demarcated sets of theories, positions in this debate lie on a continuum.
} 
defend a negative answer. A positive answer does not, however, imply that restricting immigration is desirable and should be the norm. Theorists who admit restrictions identify an area of policy discretion (Blake 2002). This area can be more or less broad. It is the space that remains once right-based claims of both would-be immigrants and residents have been satisfied. Arguably, it is also the space wherein democratic debates and procedures can lead to a defensible - more or less restrictive - immigration policy. In practice, restrictions may still be the exception for this second group of theorists but whether this is the case is left to the democratic choices of citizens.

Assuming for the moment that the latter theories are correct, what should states and their citizens do? It may be the case that the right to exclude should not be used, namely if there are further reasons to support the lifting of restrictions. This is also a politically important question and, perhaps, it is a practically more consequential one. Aside from the relatively few wouldbe migrants for whom right-based claims are prominent, e.g. refugees, the vast majority fall, according to discretion theorists, into such a grey area. This is, for instance, the case for the socalled 'economic migrants'. Should then the right to exclude be used by citizens against would-be economic immigrants? In what circumstances and on what grounds? Answers to this second set of questions are bound to depend on contingent circumstances to a greater extent than answers to the first question, which deals with the very existence of a right to exclude and thus involves basic, possibly less variable human needs and interests. Features of the international economic and political system such as the dynamic of global inequalities, the international division of labour and the expected direction of migratory fluxes arguably matter to a higher degree in the policy discretion area. Despite these contingencies, some general considerations apply to several contemporary states.

One dimension in which generalisations are possible is the expected economic effect of unrestricted migration. There is evidence that unrestricted migration would be, in the current circumstances, economically beneficial. Such evidence encompasses both empirical data and theoretical models. The economist Michael Clemens writes:

The gains from eliminating migration barriers dwarf - by an order of a magnitude or two - the gains from eliminating other types of barriers. For the elimination of trade policy barriers and capital flow barriers, the estimated gains amount to less than a few percent of world GDP. For labor mobility barriers, the estimated gains are often in the range of 50-150 percent of world GDP. (Clemens 2011, p.84)

Clemens also comments: "When it comes to policies that restrict emigration, there appear to be trillion-dollar bills on the sidewalk" (ibidem, p.84). This is the wealth that would be generated by lifting any restriction on labour mobility. Clemens' estimates can be and have been contested and, importantly, are insensitive to distributive issues. Yet there is a consensus that cross-border labour mobility is all-things-considered economically beneficial: even if the extent of its benefits is debatable and possibly lower than Clemens predicts.

Who would reap the benefits of unrestricted labour mobility? Migrants themselves are expected to gain in the first place since, as a sheer consequence of relocation, their income is expected to catch up with that of the median worker who resides in a wealthy country (Clemens et al. 2009). Moreover, there is little evidence that immigration negatively impacts wages in receiving countries. That immigration has negative wage effects in low-paid segments of the labour market has been posited by scholars (e.g. Borjas 2016, 2017) and is a

\footnotetext{
$\overline{5}$ See Milanovic (2016) for a discussion of the importance of economic migration.
} 
concept often pedalled by xenophobic politicians. Yet such effects seem to be rare, and they are far from automatic (Kennan 2017; Clemens and Hunt 2017). ${ }^{6}$ There are, of course, important negative effects in the sending countries, for instance 'brain-drain' effects, i.e. the emigration of highly trained people (Brock and Blake 2015). Yet the expectation is that the gains of unrestricted migration would be so vast that offset schema, including feasible and already existing mechanisms such as remittances, could conceivably alleviate any such damage. The main argument for lifting restrictions on immigration is hence this: open borders is the most effective way to reduce global inequalities, with few side-effects and indeed expected gains for migrants and citizens of receiving countries alike (Milanovic 2016). To be sure, discretion theorists may disagree on the extent to which domestic policy-making ought to be sensitive to such benefits, which partially accrue internationally. However, even if the domestic debate could legitimately ignore such benefits, it does not follow that it should not take them into account: it is again a case of democratic discretion. The economic evidence presented above constitutes a reason for lifting restrictions whatever one thinks of the permissibility of national partiality, i.e. the view that benefits accruing to fellow citizens, and more generally their claims, can be given some kind of priority in domestic democratic politics. ${ }^{7}$

Perhaps migration has other negative effects in receiving countries; if not, why should citizens use their discretionary power to restrict immigration as they do? Studies have indeed shown that, in several wealthy countries, it is mainly cultural worries rather than economic concerns which drive anti-immigration attitudes (e.g. Schneider 2008). Such attitudes are widespread in economically successful countries and common within well-off segments of the population. This would be puzzling if anti-immigration attitudes were chiefly driven by economic concerns. Possibly, these citizens fear that an influx of people with foreign habits and values may undermine some of the features of their social and political life which they deem important, or in fact some such features which are indeed valuable. There is a vast literature regarding the value of culture and the mechanisms by which migration could erode or, on the contrary, positively transform, the domestic culture of receiving countries: provided that any of these notions are coherent and worth-defending. ${ }^{8}$

The importance of local culture is at the core of some permissivist theories of restriction on immigration. Restrictionists must after all explain why historically contingent facts such as national borders, domestic culture and local mores matter normatively. Theorists who do not admit restrictions typically argue that any such contingent facts are irrelevant. At least, these theorists argue that the loss of cultural goods is generally trumped by the right-based claims of would-be immigrants. Let us, however, continue with the supposition that restrictions are permitted. If so, in the area of policy discretion, a cost-benefit type of analysis is in order. Potential cultural losses should be measured against the economic benefits of labour mobility. Yet the value of any specific local culture is protean and evades precise characterisation, while economic effects are more tangible and measurable. To be sure, something does not lack value just because its worth is difficult to qualify. Yet such epistemic difficulties do matter in the grey area, i.e. in political discussions about the trade-offs of immigration, and the balance should be

\footnotetext{
${ }^{6}$ For a more in-depth analysis of this literature, see Del Savio et al. (2019).

${ }^{7}$ This is not an exotic position; it describes the status quo of democratic countries. In such countries, citizens typically choose their immigration policy with no formal input of would-be immigrants. This means that immigrants' claims can, legally, be discounted. Nevertheless, there are citizens and parties who construe their political agenda around immigrants' claims. That is, they use the space of discretion to argue that immigrants' interests should also figure in domestic policy-making even if they legally need not.

${ }^{8}$ An entry point in this literature is Scheffler (2007).
} 
struck here with a three-billion bill on the sidewalk. Moreover, economic benefits occur to relatively disadvantaged groups. These benefits are not limited to the residents of receiving countries as is the fruition of local cultural goods. This is a very attractive characteristic of economic benefits for theories purporting to be impartially universalist. At any rate, as is argued above, even partialist views do not necessarily entail the idea that such considerations must be ignored: only that they can be discounted. ${ }^{9}$

From thisdiscussion, it can be concluded that citizens should not use their right to exclude economic migrants. A non-restrictive policy is desirable even if we take into account cultural worries, and in fact even if such worries have merit. In fact a non-restrictive policy would remain desirable even if its benefits were to mostly accrue abroad (and they do not) and depending on the discounting system - if such non-domestic benefits could be discounted. As far as the scholarly and policy debate is concerned, restricting migration is therefore regarded as either unjust and harmful or at least harmful. Restrictions are both unjust and harmful according to theories which do not admit restrictions plus the extant economic evidence. Restrictions are simply harmful according to most theories which do admit restrictions plus the extant economic evidence.

\section{Counting the Costs of Anti-Immigration Backlashes?}

Should we opt for less just or less beneficial policies on the basis of the expectation that a majority of citizens, ${ }^{10}$ or at least a vociferous minority of citizens, will not comply with what would be the best policy option if it were not for their expected reaction? Should migration policy continue to lag behind theory because of the fear of social instability engendered by anti-immigration backlashes?

At first sight, even if anti-immigration backlashes are predictable, it seems that their harmful consequences should not be taken into account at all in the context of these discussions. A first ostensible reason for this is that those arguing for restricting immigration and anti-immigration troublemakers are often one and the same group: or at least good allies. "If you do not give up your plan, I will make trouble; and this is a reason against your plan" is emphatically not a good argument. This first response is, however, too swift. The argument against immigration based on anti-immigration backlashes can be presented in good faith, even if perhaps good faith cannot always be assumed in this context. The defenders of this argument may, for instance, try to insulate their claims from the backlash itself: perhaps they would, at least, avoid making such claims in public debates, thereby averting the problematic self-

\footnotetext{
${ }^{9}$ Stronger partialist theories of political obligation entailing that some form of national partiality is required can be elaborated. Whether or not such theories can be defended, they would also not be incompatible with the view that the benefits of non-restrictive migration policy occurring to non-citizens matter for the formulation of domestic policy. See, for instance, Ypi (2010). Some strong partiality theorists may, however, object to the generalisation that is offered here. This is why the position in favour of lifting restriction cannot be said to be a consensus view. There is a strong convergence of views, but the convergence is not strictly speaking unanimous. ${ }^{10}$ It could be argued that, if there is a majority against immigration, what maintains the lag is just democratic legitimacy: non-restrictive migration policies are rejected by the democratic will of the citizens. While democratic will of the citizens in rich countries is part of the causal explanation of the lag, a normative interpretation of this fact will not be given here, as it is question-begging with respect to the normative debate on the right to exclude. This article is agnostic on the issue of the democratic legitimacy of nation-state-based decisions on migration policy.
} 
fulfilling nature of the argument. After all, pointing at predictable, robust patterns of human behaviour which happen independent of one's words and deeds is not coercion.

There are, however, serious difficulties with this counter-objection. It seems that such predictable and robust patterns - the anti-immigration backlashes - cannot function as background facts in normative discussions. The main reason is that they are themselves under moral scrutiny: they are, after all, the consequence of human attitudes and the choices based thereupon. These are the typical sorts of thing that are under moral scrutiny: attitudes, choices, behaviours. If this is correct, anti-immigration backlashes cannot a fortiori appear in normative discussions regarding migration. The additional reason is that the moral scrutiny of attitudes and behaviours towards immigrants belongs to very theme being discussed. This is not a distant area of morality that can be temporarily relegated to the factual background. Perhaps restrictive migration policies are unjust, harmful or both. If they are, this normative content must feature prominently in the evaluation of anti-immigration attitudes and behaviours. Any choice based on such attitudes would lead to harmful and unjust decisions: morally reprehensible decisions. Taking anti-immigration backlashes as merely the factual background seems to blatantly beg the question.

This conclusion is straightforward for theorists who, as a matter of justice, do not admit restrictions on migration. For these theorists, the harmful consequences of anti-immigration backlashes must be simply dismissed for moral reasons as they result from non-compliant behaviours that undermine just policy. Such costs cannot be employed against fundamental right-based considerations. The language of costs is not pertinent when reasoning about rights, and costs due to non-compliant behaviour are not pertinent for a still stronger reason, as this behaviour is under moral scrutiny. But even theories that do admit restrictions fare no better. Here the issue pertains to the cost-benefit analysis in the policy discretion area. For these theorists, the harmful consequences of anti-immigration backlashes can be measured against the benefits of migration. Such costs may even tip the balance in favour of more restrictive migration measures: or suggest caution and a slower pace of progress. But, as argued above, in normative discussions pertaining what policy is desirable we cannot take such circumstances for granted as if they were merely part of the factual background.

The issue of backlashes, however, resurfaces at a later stage, when we try to put the prescriptions of these theories in practice. It is, in fact, not clear what these theories actually prescribe, as they offer no guidance regarding a second-best in the face of widespread backlashes nor information about sustainable transition pathways. Instability may be so acute that the enforcement of the prescribed policy could be called into question. The problem with ignoring anti-immigration backlashes alltogether lies in the practical hollowness of such directive. We are left without guidance for stopping the troublemakers. When the sideeffects of an otherwise just or beneficial policy are predictably severe, what $i$ s the desirable policy? To be sure, such side-effects are generated by mechanisms which are questionable, i.e. non-compliant behaviours. Yet until no plans to increase compliance are presented, the prescriptions of the theory are difficult to discern. This is most clear when, as in this case, non-compliant behaviours may threaten political stability. In such conditions, not even the smooth enforcement of the theoretically more desirable policy can be taken for granted.

Reflecting on anti-immigration backlashes brings us into a well-known theoretical knot of normative theorising: one that pertains to the relation between normative theories and their practical prescriptions in the real world, or ideal and non-ideal theory. It was argued above that we have strong reasons for less restrictive anti-immigration policy (section 3 ) and that the costs of anti-immigration backlashes (as spelled out in section 2) cannot count against these reasons 
(this section above). The latter is, in the language of political philosophy, an idealist move: some important facts regarding compliance are ignored for the sake of discussing how the world should be (Valentini 2012). I do not intend, here, to contribute directly to this important methodological discussion. Yet I would like to argue that what motivates disagreements about the role of real-world constraints in normative theorising may be oftentimes a disagreement about how constraints should be conceptualised, ultimately based on different epistemological, empirical and political views.

In particular, those arguing for taking into account the costs of non-compliant behaviour, such as anti-immigration backlashes, may think that some facts about compliance - and, more general, facts about feasibility - are recalcitrant to change whatever our best political aspirations are. The question is not so much whether or not certain facts should count in normative theorising: anti-immigration backlashes cannot be measured — with the same morally charged currency, as it were - against the benefits of less restrictive immigration policy, as they are under moral scrutiny. Yet these facts nonetheless matter because and as long they cannot be changed. This may seem a mere reformulation of the aforementioned theoretical knot. For those who accept the formula 'ought implies can' indeed it is: something can be under moral scrutiny only if it can change, i.e. if it can be done otherwise, therefore the backlashes are placed under moral scrutiny only if they can be changed. Yet the new vocabulary allows us to notice something additional, namely that whether some circumstances can be changed is oftentimes a matter of degree. Recalcitrance to change can be more or less severe. It may be more or less difficult to avert particular patterns of behaviour or to change people's minds. This gradual nature of the resistance that the circumstances offer against our attempt at political transformation is practically of the utmost importance. Feasibility is not binary. The blunt alternative between can and cannot enshrined in 'ought implies can' is unable to capture such practically crucial gradations. We decide on its basis how much effort we are ready to make towards certain social and political transformations and whether we should instead reconsider our practical objectives. This focus is realist, as it asks to take into account the status quo, including considerations regarding robust, recurrent patterns of possibly non-compliant behaviour when deciding what we practically ought to do (Galston 2010; North 2010).

The approach defended here is, then, idealistic insofar it ignores a number of facts regarding compliance when discussing the question of whether a world with less immigration restrictions would be a desirable one. At the same time, the approach is robustly realist as it calls attention to the practical importance of feasibility constraints, including facts about human nature that tend to produce non-compliant behaviours. Joseph Carens (1996) argued - notably: in the context of the political theory of migration - that these two levels of idealisation need not to be seen as incompatible. And they are not, "excluding altogether absurd moral demands, which would involve breaking the laws of physics" (Valentini 2012, p. 8), as questions of feasibility are a gradual matter, including constraints on feasibility that are due to common, robust psychological features of human beings. The world would be a better place with less restrictions on immigration, but yet facts about anti-immigration backlashes are relevant when planning actions. Here I would like to add to Carens's methodological pluralism a further hypothesis regarding why disagreement on the role of factual constraints in normative discussions persists even though idealism and realism, so reconstructed, ${ }^{11}$ are not incompatible. The hypothesis is that such

\footnotetext{
${ }^{11}$ Different, intersecting problems are discussed under the label of "ideal vs. non-ideal theory debate" (Valentini 2012). The claim advanced here that the two poles are compatible pertains to the version of this debate centered on constraints and feasibility.
} 
disagreement - at least in part - may ultimately be due to a deeper divide between two sets of general attitudes towards political and social change.

These two sets of attitudes are sometimes described in terms of reformism (or progressivism) and conservatism. Progressives have, by definition, ${ }^{12}$ faith in social and political change. They believe that human behaviour is malleable and that reasons, including normative reasons, are the instruments of choice for change. The effectiveness of normative reasoning in changing attitudes and behaviours underpins the claim that change is desirable, as it ensures that the lag between ideals and reality will eventually disappear because human behaviour, driven by reason, will catch up. This is an optimistic take on transformation. Such optimism encourages the pursuit of social and political change. As far as the debate on migration is concerned, progressives typically want to overcome the status quo of restrictive norms. As progressives are optimists, they believe that anti-immigration backlashes do not belong to the factual background. Such backlashes are deviant, irrational behaviours that can be changed. If there is a lag between reason and practice - and the lag in the migration case is wide - the former will eventually pull the latter.

Political optimism, progressivism and preferences for open borders are sets of beliefs often defended in concert. There is, however, no conceptual necessity here. This is merely a family of views that fit contingently together. If the status quo was different, the progressive label would perhaps be attached somewhere else in this debate. Importantly, the facility of change is just one among several considerations that makes it desirable; hence optimism does not imply progressivism in a strong sense either. For the purposes of our practical question, the only aspect that matters is whether such optimism is well-founded: whether anti-immigration backlashes can be averted.

Conservatives take, also by definition, the opposite stance towards social and political change. They fear it. Change may cause unwanted side-effects, thus damaging the fragile edifice of society. Such damages are sometimes entirely predictable; sometimes they are harder to foresee. This suggests that a conservative would argue in the case of anti-immigration backlashes and their harmful consequences as follows. Reactions against immigration are robust social regularities. They are grounded in human nature, in ingrained human propensities such as xenophobia or the psychological coupling of in-group solidarity and out-group discrimination. These are tendencies against which reasoning in general and moral reasoning specifically are often powerless. The conservative's is hence a skeptical outlook. It treats antiimmigration backlashes as a fixed cost, as a predictable consequence of change. Skeptics suggest caution. Since the status quo is restrictive, restrictions should remain in place or be changed very slowly. Possibly, anti-immigration reactions are protecting society from unforeseen negative effects which would be generated by a too rapid change in the composition and culture of the resident population.

The conservative's is also a coherent set of views often supported together. Yet again, there is no conceptual necessity in this family of views either. If open borders were the status quo, skeptics would suggest caution in the introduction of restrictions, fearing disruption of extant and functioning patterns of cooperation. One can moreover despise particular social and political transformations even if such transformations are likely to be smooth and lack major

\footnotetext{
${ }^{12}$ This language is inspired by the analogous taxonomy regarding political attitudes towards constraints of Buchanan (2011) and Powell and Buchanan (2016), which applies to debates of biomedical human enhancement. Such language does capture some of the features of conservatism and progressivism in the historical sense. The delimitation of such currents of thought is controversial among scholars, and the language employed here is too crude for many such debates. Historically accuracy is, however, not the aim here.
} 
unwanted side-effects. For the purposes of the practical question, the only aspect that matters is whether such skepticism is well-founded: whether anti-immigration backlashes are recalcitrant to change.

Should we then be optimistic or skeptical in regard to anti-immigration backlashes? Some possible answers are discussed below. For the moment, it should be pointed out that there is a continuum between optimism and skepticism. This continuum corresponds to the gradual nature of the resistance circumstances offer against our attempts at political transformation. Political optimism and skepticism are not sets of beliefs that may be correct or not. They are rather general epistemic postures. Confronted with social transformations, optimists look for adequate tools for change and open opportunities, skeptics search instead for constraints and unseen side-effects. These are, importantly, complementary postures. The blunt can-vs-cannot divide does not once again capture the whole range of possibilities that lies between hard constraints on transformation and circumstances which can be modified at will without consequences.

Moreover, whether some patterns of behaviour are robust is an empirical question. To be sure, it is unlikely that empirical evidence will ever decide the answers to questions related to social and political transformation. Yet answers to these questions can be at least informed by scientific research. There will certainly be ample room for interpretation of the relevant evidence. This adds an epistemic layer of uncertainty that further compels us not to collapse our practical question into a neat can-vs-cannot alternative. Whether a set of circumstances can be transformed is fuzzy through and through, on the epistemic as well as the ontological side. What we lose in certainty by abandoning the precision of the can-vs-cannot distinction we do, however, gain in width. A wide range of findings regarding human behaviour and attitudes becomes relevant with the adoption of the practical perspective. Crucially, disagreement will no longer be a pure matter of normative discord. Neither will we be dealing with conflicting methodologies regarding normative reasoning. Such types of normative and methodological disagreement have often proven to be intractable. If the issue is empirical, there are instead shared standards against which we hope we can make progress. This is an attractive feature of the practical perspective, in addition to its width. ${ }^{13}$

\section{Xenophobia, Human Nature, Constraints}

If what mattered in discussions about migration policy was merely the possibility of change interpreted along the blunt can-vs-cannot divide, we could be made content by a very thin theory regarding the feasibility of change. The alternative theories would be in fact two: yes change is possible, or no, it is not. From the practical perspective, however, we want to know much more regarding how hard change will be and what instruments we can mobilise to pursue such change. The amount of evidence that would be necessary to parse in order to make satisfactory progresses on this theme is massive, and the purpose of this essay is not to attempt such a review or elaborate concrete strategies against anti-immigration backlashes. The more

\footnotetext{
${ }^{13}$ There is arguably a stronger conceptual relationship between conservatism and skepticism than between progressivism and optimism. Some scholars only classify among conservative views arguments against transformation due to the recalcitrance to change of the present circumstances, the threats of disruptive side-effects and hence the wisdom of the status quo (Hamilton 2015). This is an interesting conceptual and historical reconstruction. Nothing in the argument presented here depends, however, on whether this particular reconstruction is historically or theoretically enlightening.
} 
modest aim is to defend the view that anti-immigration backlashes lie somewhere on the continuum between fixed factual backgrounds and liquid circumstances which can be safely ignored. In doing so, it will hopefully become clear how this type of research can be practically helpful. The focus is, more specifically, on some recent research on exclusivism and xenophobia. A draft of a biocultural theory thereof will be sketched on this basis. Such a theory needs expansion and many clarifications but its general outline should suffice for the current demonstrative purposes, namely showing that thinking about constraint in a gradualist manner can be practically fruitful and dispel some disagreement about the place of factual constraints in political theorising. Xenophobia is not the only driver of anti-immigration backlashes. ${ }^{14}$ It is, however, a good candidate for being the kind of recurrent feature of social circumstances that should figure in discussions about migration.

One difficulty with research on xenophobia is the researchers' different disciplines and their lack of communication. This is also a notorious feature of research on racism (Machery and Faucher 2004), with which research on xenophobia partially overlaps. One group of researchers focuses on the political and cultural dynamics which promote xenophobia. Among these are sociologists, political scientists and cultural anthropologists. According to this literature, xenophobia is socially constructed: the content and cultural prevalence of xenophobic attitudes depend on who wields the power and their interests or other social factors. ${ }^{15} \mathrm{~A}$ second group of researchers focuses on the biological and psychological determinants of the prevalence of xenophobia. According to this literature, the success of xenophobic attitudes, and possibly their content, also depends on ingrained features of human psychology.

Studies on psychology, neurobiology and behaviour lend credence to the view that human prosocial behaviour may be exclusivist: prosocial feelings and behaviours are more easily directed at group members and denied to out-group strangers. ${ }^{16}$ Some basic mechanisms which underpin group-based biases are conserved across vertebrates, suggesting ancient evolutionary roots (Kavaliers and Choliers 2017). In-group favouritism appears early in human development as do cooperative attitudes (Warneken et al. 2007; Schmidt et al. 2012; Engelmann et al. 2013; Hamlin et al. 2013). Perceptions of between-group competition increases within-group cooperation in economic games (Burton-Chellew and West 2012). Much is also known about the neurophysiology of such behaviours. The neurotransmitter oxytocin, which is known to increase social bonding, supports in-group bias by promoting the positive evaluation of in-groups as opposed to out-groups. Selection for prosocial psychology is also thought to promote oxytocin expression via the reduction of testosterone, which is antagonistic to oxytocin (De Dreu 2012). At a psychological level, humans tend to dehumanise out-groups: thereby facilitating aggression (Hodson et al. 2014). Importantly, it has been

\footnotetext{
${ }^{14}$ For instance, Jonathan Haidt argues that a central driver of anti-immigration backlashes is a type of moralistic reaction. Individuals whose values revolve around the importance of authority, the significance of community and a sense of the sacred repudiate what they consider an erosion of national communities. Such a reaction pitches them against individuals whose values, as a result of economic transformation, have instead shifted towards a cosmopolitan mindset centred on harm and fairness (Haidt \& Graham 2007; Haidt 2016). This analysis complements in important ways theories based on xenophobia, but there is no space to expand on Haidt's theory in this article.

${ }^{15}$ An enlightening exposition of this approach is found in Balibar (1991). He specifically argues that research on the biological and psychological underpinnings of xenophobia is employed by "differentialist" neo-racists to spread anti-immigrationist theories, namely the skeptical view that heterogeneous groups cannot and hence should not co-exist. "The neo-racist ideologues are not mystical heredity theorists, but 'realist' technicians of social psychology" (Balibar 1991, p.23).

${ }^{16}$ For a general review and further references, see Hare (2017).
} 
known since the early days of exclusivism research (Tajfel 1978) that such us-vs-them psychology and behaviour can be triggered, in humans, by minor and arbitrary distinctive marks, such as clothing or artificial groupings. Finally, ethnographic comparisons show changes in social structure consistent with the coevolution of increased cooperative capacities and parochialism (Boehm 2001). Theories and data hence converge on the view that prosocial psychology and behaviour are exclusivist (Haidt and Graham 2009; Bohem 2012; Sapolsky 2017).

Theoretical considerations regarding human evolution strengthen the exclusivist view of human prosociality. It has been suggested that exclusivist prosociality could have resulted from the endemic conflicts among bands of hunter-gatherers and the selection between groups that it generated (Choi and Bowles 2007). Interestingly, such a scenario is predicated on the key role that culture and social construction played in such processes. Group selection is generally thought to be a weak force in biological evolution unless there are mechanisms in place which demarcate human groups, increase their homogeneity and reinforce the punishment of antisocial behaviour. Human culture provides just such a mechanism (Richerson and Boyd 2005). Behavioural-ecological hypotheses have also been advanced to explain the us-vs-them psychological and behavioural syndrome. For example, in the parasite-stress theory, a fear of foreigners is adaptive in the presence of infective epidemics, as it helps minimise the chances of contagion (Thorhnill and Fincher 2014). These theories also predict behavioural flexibility to be a feature of the us-vs-them syndrome (Jaeggi et al. 2016). Human coalitions change frequently and inter-group exchanges in a context of multilevel, nested group structure are much older than once thought. In human evolutionary history, wars and epidemics were interspersed with frequent and beneficial exchanges of goods and partners (Pisor and Surbeck 2019).

Two features of this general picture of the us-vs-them syndrome stand out with regard to anti-immigration backlashes. The first relevant feature is the facility by which us-vs-them reactions are evoked and the plasticity of the grouping cues upon which such reactions are triggered. It would be worrisome if humans tended to automatically and persistently focus on specific phenotypic signatures to establish who is an in-group and who is not, especially if these phenotypic signatures were associated with classifications which have favoured and still favour oppression, e.g. skin colour. This is a hypothesis that needs elaboration. ${ }^{17}$ Yet the seemingly propitious plastic nature of us-vs-them reactions also makes them amenable to being hijacked. In particular, the evocation of an ethno-nationalist identity can be, on this basis, arbitrary but nonetheless effective. National borders are just such an arbitrary demarcation that can be employed to depict a homogeneous community warring against the out-groups. The second relevant feature is the exclusivist nature of sociality itself, which indeed corroborates the claim that homogeneity and everyday sociality are connected. Diversity can weaken prosocial attitudes and behaviours because the very perception of group divisions makes cross-group cooperation more difficult. Once an out-group is tagged as such, uncooperative behaviours such as cheating or outright aggression become more frequent. The politically and socially harmful consequences of anti-immigration backlashes are hence psychological and behavioural tendencies which are apparently common and robust.

\footnotetext{
${ }^{17}$ The plasticity of us-vs-them psychology is not incompatible with the presence of racialist tendencies, at least if these tendencies are not immune to being overridden by other clues. See Machery and Faucher (2004), for a discussion of the evidence. Humans seem to process racial clues in coalitional psychology but evidence of a specific tendency that favours such classification is controversial, both empirically and on theoretical grounds.
} 
The spread of xenophobic attitudes, however, does not merely depend on the presence of such ingrained features. The causal network is extremely complicated. Xenophobic campaigns are often orchestrated, as discussed above, by populist politicians pursuing their own agendas or acting as agents of powerful principals. These actors understand that xenophobia can be promptly evoked: hatred for foreigners is socially constructed, but easily so. In this sense, biological and social constructionist accounts of xenophobia - when properly understood are not merely compatible: they support each other. Xenophobia is a biocultural construct. Diffidence towards out-groups is reconstructed again and again in the lifetime of each xenophobic individual on the basis of features of human psychology and political dynamics. Interestingly, if the scenario of warring culturally demarcated groups is correct, the evolution of xenophobia has been biocultural too: the social construction of groups steered human evolution. Xenophobia is hence both evolutionarily and developmentally biocultural.

I would like to argue that the lack of communication between biological and social constructionist approaches to this and other topics is due to a series of conceptual misunderstandings regarding the politics of such research ultimately based on the distinction between a reformist and a conservative attitude as I have described in the previous section. Biological studies of human propensities are associated with skepticism towards change and conservatism, while social constructionist approaches are associated with optimism and progressivism. Such associations function roughly as follows. Biology and psychology are the realm of infeasibility: of constraints on political transformation (of 'cannot'). Our evolved biological traits are universal and recalcitrant to change. In some versions of these views, such traits are written in the genes. Social construction is instead the realm of human action and political change (of 'can'). Cultures and political arrangements are after all variable, this is just what social anthropology demonstrates, and hence traits that are culturally induced and transmitted are amenable to transformation. Cultural variability shows that things can be done otherwise. This is a recurrent pattern of reasoning. None of these claims, conceptual associations and inferences can however be rescued. They have, unfortunately, been drawn in normative theorising in just this rough way. ${ }^{18}$ Yet they have no basis whatsoever in contemporary scientific research. There is no space to delve into these issues here, but a brief recapitulation suffices for our purposes. Biology and psychology study variability as much as universal traits. The evolutionary antiquity of a certain trait does not say much, as such, about its recalcitrance to change. Evolutionary theories of human biology invoke culture through and through, both in ontogeny and development: exclusivism is in fact a case in point if the hypothetical evolutionary scenarios mentioned above are correct. In development, the reliable occurrence of a trait - including psychological and behavioural traits - is sometimes based on the inheritance of genetic resources and sometimes on recurring features of the environment. This includes social and political circumstances. On the one hand, there is much variability in nature. On the other, much robustness is due to cultural and political factors. ${ }^{19}$ Such distinctions cannot be neatly put in place for a large class of phenomena, including many developmental and evolutionary processes.

Far from being an interactionist triviality, the possibility that recurring features of the social and political environment generate regularities is crucial. It implies that the identification of cultural and political influences on the development of a trait does not equate to the discovery

\footnotetext{
$\overline{18}$ One crude example is in Singer (1999). For a devastating critique, see Kitcher (2002).

${ }^{19}$ When the role of cultural factors in the occurrence of social and behavioural regularities is acknowledged, as for instance in discussions of between-population diversity, such factors can also be assimilated into what is natural in the hasty equation 'natural = recalcitrant to change': "Culture can also function like a nature, and it can in particular function as a way of locking individuals and groups a priori into a genealogy, into a determination that is immutable and intangible in origin" (Balibar 1991, p.22).
} 
of its malleability. Social construction is not, simply, the realm of political action: it sets its own constraints. Let us for instance suppose that class division and class domination are quasiuniversal features of human societies, as Marxists believe. ${ }^{20}$ If the powerful have an interest in seeding divisions among their subordinates, the presence of xenophobia is then expected to be a recurring regularity for thoroughly political reasons: powerful elites have the interest in evoking xenophobic attitudes in the population and, importantly, the resources to do so. This is a robust mechanism that seems to depend on the reliable occurrence of inequalities of power. Interestingly, the biological resources on the basis of which xenophobia is construed provide instead room for manoeuvre, as the us-vs-them syndrome is distinctively plastic. A biocultural account of xenophobia does not, therefore, simplistically vindicate optimistic or skeptical perspectives regarding anti-immigration backlashes.

Regularities in human sociality can be recalcitrant to change or, on the contrary, easy to disrupt. Such recalcitrance does not, however, map onto a crude distinction between natural propensities and social construction. In the previous section, it was argued that the optimist/skepticist divide should not be conflated with the distinction between progressive and conservative. These distinctions should also not be equated with different approaches towards studying social regularities. All such studies matter, as they all provide a more precise depiction of opportunities and constraints for change. The conceptual disentanglement of conservatism, progressivism, optimism, skepticism, social constructionist and biological approaches promises pay-offs. Buchanan and Powell (2018) have recently developed a naturalistic account of moral progress that focuses on exclusivism and inclusivism and, therefore, that partly overlaps with the themes discussed in this paper. They claim, as does this article, that an attractive feature of naturalistic approaches is that they provide tools for transformation - in their case, moral progress - which are often neglected. These tools are neglected because biological factors in political dynamics are often thought to be a source of constraints only, by optimists and skeptics alike: the former because they tend to trust the power of reason, the latter because they tend to distrust it. Buchanan and Powell point out that this is a mistake. If, for instance, exclusivist attitudes evolved — and are still triggered — in contexts of inter-group conflicts (as in group-selectionist theories) or endemic epidemics (as in the parasite-stress theory), the removal of such contexts or even the removal of the perception thereof may be an effective strategy to promote the spread of less exclusivist attitudes and behaviours.

These hypotheses are empirically controversial and possibly wrong. Romano et al. (2017) did not confirm these hypotheses in a recent article dedicated to the factors that promote prosocial parochialism. Importantly, they pointed out the importance of interpersonal variability, with people dispositionally more cooperative being able to transcend more easily group boundaries. On this basis, a further area of research that is practically relevant would the elaboration of strategies against xenophobia that work in human populations that are intrinsically variable: interindividual differences matters as much as individual plasticity when devising courses of action. Inter-populational variability is a third relevant area, alongside human universals and interindividual variability. It is well-known that otherwise similar European countries differ massively with respect to attitudes towards immigration. It has been hypothesized (Messing and Sagvari 2018) that such differences may depend on factors such as the perception of security, the relevance of values such as humanitarism and equality in public discourse, and the presence of immigrants (inversely correlated with positive attitudes towards immigration). This is important data to eviscerate the question of what triggers the dispositions to include or exclude perceived outsiders. The potential relevance of security, for instance, gives further credibility to the hypothesis that the perception of threats may be

${ }^{20}$ This is a simplified hypothesis that does not intend to capture the nuances of the Marxist debate on this point. 
important in the development of a xenophobic attitudes. The prominent role of public discourse is in turn aligned with recent approaches to psychological development that underline the crucial ontogenetic role of social norms (e.g. Tomasello 2016).

Whatever the empirical merits of the theories they decided to focus upon, ${ }^{21}$ Buchanan and Powell's approach illustrates the benefit that empirical psychology and other beahvioural sciences can bring to discussions about transformation, namely a wider variety of instruments for political change. This might be surprising for those who equate the realm of human nature (or even of scientific facts tout court) with that of necessity and conservatism, and social constructionist approaches with optimism and progressivism. The biocultural theory of xenophobia illustrates the theoretical and practical shortcomings of such views. Such a naturalistic approach is being adopted in discussions of cosmopolitanism and its (lack of) motivational force (Cameron 2018) and can be equally useful in discussions of immigration policy. For the sake of the argument presented here, the important lesson of this approach is a gradualist and naturalistic take on the nature of real-world constraints on political intervention. Human nature matters practically, but not as hard constraint: rather, the plastic, variable (both inter-individually and inter-populationally) nature of human psychology offers as much avenues for interventions as hindrances to be overcome.

\section{Conclusions}

Anti-immigration backlashes are not an inevitable feature of sociality necessitated by unyielding human tendencies such as xenophobia. Such backlashes cannot, however, be ignored on the grounds that they are proscribed by our best normative theories when devising plans for change. Humans are sensitive to the kind of reasons which issue from these theories. They are also vulnerable to the orchestrated evocation of xenophobia by shrewd politicians, which is a predictable feature of political dynamics and hence the environment where individual attitudes develop. The harmful consequences of xenophobic attitudes are also channelled by the flexibility of us-vs-them psychology and the coupling of prosociality and exclusivism, thus rendering their harmful consequences predictable. In normative discussions about migration policy, anti-immigration backlashes and their harmful consequences should therefore feature prominently at the implementation stage, even though such facts are themselves objects of normative scrutiny and indeed based on reprehensible attitudes and behaviours and hence a void guidance regarding how the world should be. Such backlashes should be conceived as potential adversities against which proponents of non-restrictive migration policy had better prepare contingency plans. These plans should include, but are not limited to, moral reasoning and education. They may encompass other means of intervention which tackle the further determinants of human attitudes and behaviours towards strangers, as sentiments and emotions. In the previous section several such factors, admittedly controversial, were discussed: the perception of intergroup conflicts (real or imagined), the evocation of risks related to contagion and epidemic, the presence of threatened, and defensible resources, among the drivers of pro-social parochialism and open violence against outsiders. Policy makers should attend to such factors and their perception alongside the public exercise of political reasoning. Population variability also matters, insofar targeted strategies aimed at different psychological profiles may be needed.

\footnotetext{
${ }^{21}$ The biocultural approach defended by Buchanan and Powell centres on the plasticity of human development and has major similarities with the theory sketched here. They claim, however, that exclusivist tendencies are adaptively plastic. This claim is unsubstantiated. Moreover, they employ the language of an 'anomalous' nature of inclusivism that arguably borrows from discredited types of evolutionary explanations. Unfortunately, there is no space here to discuss these issues further.
} 
What is feasible or not should feature prominently in discussions about what we should do. This is not because only what is feasible can be normatively required: the sorts of hard constraints that are relevant in this sense are seldom interesting in political theorising, and psychological constraints are never hard constraints in this sense. Rather, a focus on feasibility and its gradual nature brings to light obstacles and opportunities of practical importance. The search for such opportunities and obstacles is integral to discussions of social and political transformations. We want to know how we can go from here to the state of affairs we desire, how much effort is needed, and whether change will be sustainable and resilient. Accessibility, costs and stability - ergo feasibility - are practically consequential issues. Feasibility matters because facts, including facts about the functioning of human interactions, place constraints on political ideals. There are, however, two distinct senses of 'constraint' that need be distinguished. For those who think that descriptive knowledge only matters via the formula 'ought implies can', 'constraint' has a strong meaning: descriptive knowledge is only useful if it is evidence of strict infeasibility. ${ }^{22}$ This is, as it were, a capital-c sort of constraint. It can be doubted that much empirical social and behavioural science entails the existence of such constraints. Many claims that they do may be the result of unilateral skepticism towards transformation. This article is dedicated to small-c constraints: obstacles, aspects of society which resist change and side-effects. They are no less important, in fact they may be more important than constraints for planning and action. Also, a much bigger chunk of descriptive knowledge is relevant in the search of these small-c constraints. The very boundary between normative and descriptive research becomes less sharp here as interests, bodies of knowledge, even methodologies partially overlap. Perhaps normative theorising is just comparatively more explicit on - and dedicates more effort to - ideals, values and aims.

Both the optimistic and the skeptical epistemic posture towards issues of feasibility are useful for the research of small-c constraints, as they can reciprocally illuminate their respective black spots. The search can moreover become wider if a number of common assumptions which accompany political optimism and skepticism are abandoned. Section 4 has shown that optimism and skepticism are in principle independent of politically conservative or progressive stances. Section 5 has elaborated on the argument that optimism and skepticism have little to do with bio-psychological or social constructionist methodologies in the study of human societies. A more specific claim of the article is that optimism and skepticism should be independent of particular normative theories regarding migration policy (section 3 and 4). A fully-fleshed biocultural study of xenophobia will be a proof-of-principle of such a wider approach if it opens practical avenues for change and, specifically, for averting anti-immigration backlashes. The lag between ideal and actual policy can only be closed if nets are cast far and wide.

Funding Information Open Access funding provided by Projekt DEAL.

Open Access This article is licensed under a Creative Commons Attribution 4.0 International License, which permits use, sharing, adaptation, distribution and reproduction in any medium or format, as long as you give appropriate credit to the original author(s) and the source, provide a link to the Creative Commons licence, and indicate if changes were made. The images or other third party material in this article are included in the article's Creative Commons licence, unless indicated otherwise in a credit line to the material. If material is not included in the article's Creative Commons licence and your intended use is not permitted by statutory regulation or exceeds the permitted use, you will need to obtain permission directly from the copyright holder. To view a copy of this licence, visit http://creativecommons.org/licenses/by/4.0/.

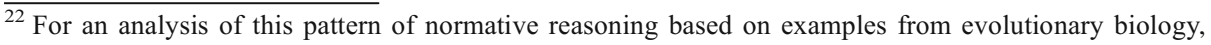
see Levy (2018). 


\section{References}

Alesina A, Glaeser E, Sacerdote B (2001) Why Doesn't the US have a European-style welfare system? NBER Working Paper, 8524

Alesina A, Glaeser E (2004) Fighting poverty in the US and Europe: a world of difference. Oxford University Press, Oxford

Balibar E (1991) “Is there a 'neo-racism'?” In Wallerstein IM, Balibar E. 1991. Race, nations, and class: ambiguous identities. London: Verso, pp. 17-28

Bertram C (2018) Do states have the right to exclude immigrants? Polity, Cambridge

Blake M (2002) Discretionary migration. Philos Top 30(2):273-289

Blake M (2013) Immigration, jurisdiction, exclusion. Philos Public Aff 41(2):103-130

Blake M (2016) Migration, mercy, love, and carrier sanctions. Talk at the University of Washington, available online at: https://uchv.princeton.edu/file/1446/download?token=quIVSrKZ

Boehm C (2001) Hierarchy in the forest: the evolution of egalitarian behaviour. Harvard University Press, Cambridge, MA

Boehm C (2012) Moral origins: the evolution of virtue, altruism and shame. Basic books, New York

Borjas G (2016) We wanted workers. Norton \& Company, New York

Borjas G (2017) The wage impact of the Marielitos: a reappraisal. ILR Review

Bowles S, Gintis H (2011) A cooperative species. Princeton University Press, Princeton

Brock G, Blake M (2015) Debating the brain drain. Oxford University Press, New York

Buchanan A (2011) Beyond humanity? : The ethics of biomedical enhancement. Oxford University Press, Oxford

Buchanan A, Powell R (2018) The evolution of moral progress. Oxford University Press, New York

Burton-Chellew MN, West SA (2012) Pseudocompetition among groups increases human cooperation in a public-goods game. Anim Behav 84:947-952

Cameron J (2018) Communicating cosmopolitanism and motivating global citizenship. Political Studies 6(33):1-17

Carens J (1996) Realistic and idealistic approaches to the ethics of migration. Int Migr Rev 30(1):156-170

Carens J (2013) The ethics of immigration. Oxford University Press, Oxford

Choi JK, Bowles S (2007) The coevolution of parochial altruism and war. Science 318:636-640

Clemens M (2011) Economics and emigration: trillion-dollar bills on the sidewalk? J Econ Perspect 25(3):83-106

Clemens M. A, Hunt J (2017) The labor market effects of refugee waves: reconciling conflicting results. NBER Working Paper, 23433

Clemens M, Montenegro C, Pritchett L (2009) The place premium: wage differences for identical workers across the US border. HKS Faculty Research Working Paper Series RWP09-004

Cole P (2000) Philosophies of exclusion: Liberal political theory and immigration. Edinburgh Press, Edinburgh

Del Savio L, Cavaliere G, Mameli M (2019) Migration and cooperative infrastructures. Philosophy \& Technology 32(3):425-444

De Dreu CK (2012) Oxytocin modulates cooperation within and competition between groups: an integrative review and research agenda. Hormones and Behaviour 61:419-428

Engelmann JM, Over H, Herrmann E, Tomasello M (2013) Young children care more about their reputation with ingroup members and potential reciprocators. Dev Sci 16:952-958

Fukuyama F (1996) Trust: social virtues and the creation of prosperity. Free Press Paperbacks, New York

Galston W (2010) Realism in political theory. Eur J Polit Theo 9(4):385-411

Haidt J, Graham J (2009) Planet of Durkheimians: where community, authority, sacredness are foundations of morality. In Jost JT, Kay AC, Thorisdottir H. 2009. In: Social and psychological bases of ideology and system justification. Oxford University Press, New York

Haidt J (2016) When and why nationalism beats globalism. The American Interest 12(1), published on July 10 , 2016

Hamilton A (2015) Conservatism. In: Zalta E (ed) The Stanford encyclopedia of philosophy Online resource: https://plato.stanford.edu/entries/conservatism/

Hamilton K, Helliwell J, Woolcock M (2017) Social capital, trust, and wellbeing in the evaluation of wealth. World Bank policy research working paper n 7707

Hamlin JK, Mahajan N, Liberman Z, Wynn K (2013) Not like me = bad: infants prefer those who harm dissimilar others. Psychol Sci 24:589-594

Hare B (2017) Survival of the friendliest: Homo sapiens evolved via selection for pro-sociality. Annu Rev Psychol 68:155-186

Hodson G, Kteily N, Hoffarth M (2014) Of filthy pigs and subhuman mongrels: dehumanization, disgust, and intergroup prejudice. Testing, Psychometrics, Methodology in Applied Psychology 21:267-284

Huemer M (2010) Is there a right to immigrate? Soc Theory Pract 36(3):429-461 
Kavaliers M, Choliers E (2017) Out-group threat responses, in-group Bias, and Nonapeptide involvement are conserved across vertebrates: (a comment on Bruintjes et al., "out-group threat promotes within-group affiliation in a cooperative fish"). Am Nat 189(4):453-458

Kennan J (2017) Open borders in the European Union and beyond: migration flows and labor market implications. NBER Working Paper, 23048

Kitcher P (2002) Peter Singer, a Darwinian left: politics, evolution, and cooperation. Ethics. 112(4):861-863

Kymlicka W (2015) Solidarity in diverse society: beyond neoliberal multiculturalism and welfare chauvinism. Comparative migration studies 3:17. https://doi.org/10.1186/s40878-015-0017-4

Levy A (2018) Evolutionary models and the normative significance of stability. Biology \& Philosophy 33:33-20. https://doi.org/10.1007/s10539-018-9643-1

Machery E, Faucher L (2004) 'Why do we think racially? A critical journey in culture and evolution'. In Cohen H, Lefebvre C. Categorization in cognitive sciences, Amsterdam: Elsevier

Messing V, Sagvari B (2018) Looking behind the culture of fear. Cross-national analysis of attitudes towards migration in Europe. Budapest, Friedrich-Ebert Stiftung

Milanovic B (2016) Global inequality. Harvard University Press, Cambridge, MA

Miller D (2005) Immigration: the case for limits. In: Cohen A, Wellman C (eds) Contemporary debates in applied ethics. Blackwell, Oxford

Mudde C (2007) Populist Radical Right Parties. Cambridge University Press, Cambridge

Mudde C, Kaltwasser CR (2013) Populism and (liberal) democracy: a framework for analysis. In: Mudde C, Kaltwasser CR (Eds) Populism in Europe and America: Threat or correctvie for democracy? (pp. 1-26) Cambridge University Press, Cambridge

Müller JW (2017) What is populism? Penguin books, London

North R (2010) Political realism: introduction. Eur J Polit Theo 9(4):381-384

Oberman K (2016) 'Immigration as a human right'. In Fine S, Ypi L. 2016. In: Migration in political theory: the ethics of movement and membership. Oxford University Press, Oxford, p 2016

Pisor A, Surbeck M (2019) The evolution of intergroup tolerance in nonhuman primates and human. Evol Anthropol 28:210-223

Pew Research Center (2018) Nationalism, immigration and minorities. Online resource: https://www.pewforum. org/2018/05/29/nationalism-immigration-and-minorities/

Powell R, Buchanan A (2016) 'The evolution of moral enhancement'. In: Clarke S, Savulescu J, C. Coady AJ, Giubilini a, Sanyal S (eds.), The Ethics of Human Enhancement: Understanding the Debate, Oxford: Oxford University press pp. 239-260

Rice TW, Feldman JL (1997) Civic culture and democracy from Europe to America. J Polit 59(4):1143-1172

Richerson PJ, Boyd R (2005) Not by genes alone: how culture transformed human evolution. University of Chicago Press, Chicago, IL

Romano A, Balliet D, Yamagishi T, Liu J (2017) Parochial trust and cooperation across 17 societies. PNAS 114(48):12702-12707

Sapolsky RM (2017) Behave: the biology of humans at our best and worst. Penguin Press, New York

Schaeffer M (2013) Ethnic diversity, public goods provision and social cohesion: lessons from an inconclusive literature. WZB discussion paper, no. SP VI-103

Scheffler S (2007) Immigration and the significance of culture. Philos Public Aff 35(2):93-125

Schmidt MF, Rakoczy H, Tomasello M (2012) Young children enforce social norms selectively depending on the violator's group affiliation. Cognition 124:325-333

Schneider S (2008) Anti-immigrant attitudes in Europe: Outgroup size and perceived ethnic threat. Eur Sociol Rev 24(1):53-67

Singer P (1999) A Darwinian left: politics, evolution, cooperation. Weidenfeld and Nicholson, London

Slobodian Q (2018) Neoliberalism's populist bastards. Online resource: https://www.publicseminar.org/2018/02 /neoliberalisms-populist-bastards/

Tajfel H (ed) (1978) Differentiation between social groups: studies in the social psychology of intergroup relations. Academic Press, London

Tomasello M (2016) A natural history of human morality. Harvard University Press, Cambridge, MA

Thorhnill R, Fincher C (2014) The parasite-stress theory of values and sociality. Springer, New York

Valentini L (2012) Ideal vs. non-ideal theory: a conceptual map. Philos Compass 7(9):654-664

Van der Meer T, Tolsma J (2014) Ethnic diversity and its effects on social cohesion. Annu Rev Sociol 40:459478

Walzer M (1995) Spheres of justice: a defence of pluralism and equality. Blackwell, Oxford

Warneken F, Hare B, Melis AP, Hanus D, Tomasello M (2007) Spontaneous altruism by chimpanzees and young children. PLoS Biol 5:e184

Wellman CH (2008) Immigration and freedom of association. Ethics 119(1):109-141 
Urbinati N (2017) Democracy disfigured: opinion, truth, and the people. Harvard University Press, Cambridge, Mass Jaeggi AV, Boose KJ, White FJ et al (2016) Obstacles and catalysts of cooperation in humans, bonobos, and chimpanzees: behavioural reaction norms can help explain variation in sex roles, inequality, war and peace. Behaviour 153:1015-1051

Ypi L (2010) Justice and morality beyond näive cosmopolitanism. Ethics \& Global Politics 3(3):171-192

Publisher's Note Springer Nature remains neutral with regard to jurisdictional claims in published maps and institutional affiliations. 